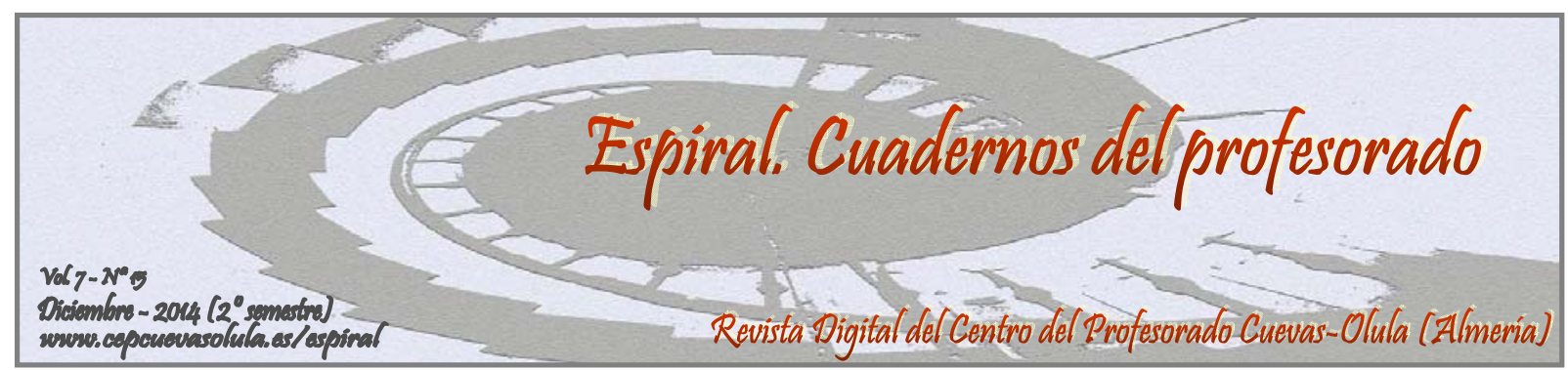

\title{
EL BUCEO EN LA ENSEÑANZA SECUNDARIA: UNA PROPUESTA PRÁCTICA
}

\author{
SCUBA DIVING IN SECONDARY SCHOOL: A PRACTICAL PROPOSAL \\ Javier Aguilar Sánchez y Victoria Eugenia Machota Blas
}

IES D. Antonio Hellín Costa, Puerto de Mazarrón, Murcia, España

RESUMEN: La presente comunicación propone el buceo como una propuesta práctica dentro del área de Educación Física en Educación Secundaria Obligatoria. Para la práctica del buceo la Región de Murcia ofrece múltiples posibilidades debido a la riqueza marina que posee. Se pretende ofrecer a los alumnos la posibilidad de iniciarse en esta actividad para contribuir a consolidar la práctica deportiva en el tiempo libre y de ocio. Todo esto sin olvidar la importancia de la conservación y mejora del medio natural. El diseño de la propuesta práctica se ha realizado teniendo en cuenta la legislación vigente y la realidad educativa.

Palabras clave: buceo, unidad didáctica, Educación Física, adolescente.

ABSTRACT: This presentation introduces the sport of scuba-diving as a practical proposal in the area of Physical Education in Secondary School. The Region of Murcia offers multiple possibilities to practice this activity due to the marine variety that it possesses. The aim is to give the students the opportunity to initiate themselves in scuba-diving and consolidate this sport as an outdoor activity option for their free and leisure time. In addition, it fosters the importance of preserving and improving the natural environment. The design of this practical proposal has been made taking into account the current educational legislation and the educational reality.

Key words: Scuba-diving, teaching unit, Physical Education, teenager.

Aguilar Sánchez, J. y Machota Blas, V. E. (2014). Actividad físico-educativa en el medio natural: influencia de práctica física sobre la condición física en mujeres mayores. Espiral. Cuadernos del Profesorado, 7(15), 70-74. Disponible en: http://www.cepcuevasolula.es/espiral

Fecha de recepción: 07/03/2014

Fecha de aceptación: 29/07/2014
Enviar correspondencia a: jaguilarsanchez@ugr.es

\section{1.- INTRODUCCIÓN}

Las actividades físicas en el medio natural (AFMN) son aquellas que se realizan en un entorno no urbanizado, generalmente no regladas, que presentan la característica esencial de que el clima y el tiempo las condicionan, y los practicantes sólo pueden resguardarse parcial y limitadamente (Funollet, 2004). En los últimos años existe cierta nostalgia hacia todo lo natural debido, entre otros factores, a la monotonía de la vida diaria. Existe una necesidad de huir de todo lo cotidiano y buscar un reencuentro con el medio natural. En esta línea, Guillén, Lapetra y Casterad (2000) indican que la práctica de actividades en la naturaleza supone para el ser humano una experiencia muy intensa y gratificante en vivencias, ya que éstas se producen en espacios no habituales, novedosos y desconocidos. 
Acercándonos al ámbito educativo, Miguel (2001, p. 47) afirma que AFMN son "aquellas actividades eminentemente motrices llevadas a cabo en un medio natural con una clara intención educativa". Las actividades en la naturaleza y los deportes de aventura son contenidos que cada vez están adquiriendo más peso en las programaciones, desbancando a otros como los deportes colectivos y el atletismo (Granero, Baena y Martínez, 2010) debido en parte, a que los contenidos "tradicionales” ya no colman las expectativas del alumnado actual (Arroyo, 2010). En este sentido, el Decreto 291/2007, por el que se establece el currículo de la Educación Secundaría Obligatoria en la Comunidad Autónoma Región de Murcia, hace referencia a las AFMN dentro de los objetivos de etapa. El citado Decreto también establece un bloque de contenidos de Actividades en el medio natural para cada uno de los cursos de la Educación Secundaria Obligatoria (ESO).

Las AFMN tienen un amplio valor educativo y presentan múltiples ventajas para incluirlas en los centros escolares. Entre ellas, destaca la posibilidad de la interdisciplinariedad con otras materias presentes en la etapa. Asimismo, estas actividades pueden transmitir una serie de valores y hábitos muy útiles para la escuela actual como la convivencia escolar, coeducación, sociabilidad, cooperación, lealtad, compañerismo, esfuerzo colectivo, convivencia, amistad, responsabilidad, etc. (Granero y Baena, 2007). Adicionalmente, estas prácticas pueden contribuir de manera importante a la consecución de todas las competencias básicas (Baena y Granero, 2011). En definitiva, las actividades en la naturaleza deberían cobrar una mayor importancia en el ámbito escolar (Vaquero-Cristóbal et al. 2013).

En concreto, la presente propuesta práctica pretende la inclusión de un contenido novedoso en el ámbito escolar: el buceo. La propuesta se ha realizado en un municipio costero de la Región de Murcia.

\section{2.- PROPUESTA PRÁCTICA. DISEÑO DE LA UNIDAD DIDÁCTICA}

\section{Contextualización y justificación}

La presente Unidad Didáctica (UD) se ubica en el tercer trimestre y está diseñada para un curso de $4^{\circ}$ de ESO. Para su elaboración se han tenido en cuenta las características socio-ambientales del entorno. El centro educativo donde se realizó es el IES D. Antonio Hellín Costa, situado en el Puerto de Mazarrón (sureste de la Región de Murcia). El instituto está ubicado en una zona costera idónea para la práctica del buceo y del submarinismo. Asimismo, existen numerosos centros de buceo (en esta y en otras localidades cercanas) que intentan promocionar la práctica de este deporte en toda la zona. La UD ha sido elaborada respetando el Proyecto Educativo de Centro y la actividad fue incluida en la Programación Didáctica del Departamento de Educación Física, teniendo además en cuenta el currículo establecido en el Decreto 291/2007.

\section{Competencias básicas desarrolladas}

Según el anexo 1 del Real Decreto 1631/2006, "la incorporación de las competencias básicas al currículo permite poner el acento en aquellos contenidos que se consideran imprescindibles". En concreto, la presente UD contribuye al desarrollo de las siguientes competencias básicas:

- Conocimiento e interacción con el mundo físico: a través de la UD se intenta concienciar a los alumnos del uso responsable del medio natural. Igualmente, se pretende inculcar a los discentes la importancia de la adquisición de hábitos saludables de ejercicio físico para la ocupación del tiempo de libre y de ocio.

- Competencia social y ciudadana: la práctica de este deporte va a contribuir al desarrollo de esta competencia a través del desarrollo de valores como la integración, el respeto, cooperación, etc.

- Competencia lingüística: se contribuye a la consecución de esta competencia por medio del aprendizaje de vocabulario específico relacionado con las AFMN y con el buceo.

- Autonomía e iniciativa personal: la práctica de este deporte supone asumir ciertos "riesgos" para los estudiantes, debido a que se desarrolla en un entorno "desconocido" para 
ellos. La superación de estas sensaciones forma a los alumnos en su autonomía e iniciativa personal.

- Competencia para aprender a aprender: esta competencia se trabaja en la medida en que el alumnado sea capaz de regular su propio aprendizaje.

\section{Objetivos}

Partiendo del Proyecto de Centro, de los Objetivos Generales de Etapa para la ESO (Real Decreto 1631/2006) y de los Objetivos de Área para Educación Física (Decreto 291/2007), se han diseñado los siguientes objetivos didácticos:

a) Conocer los orígenes y evolución del buceo, así como sus fundamentos físicos y fisiológicos.

b) Conocer los materiales y medidas de seguridad necesarias para la práctica del buceo. Identificar los peligros que pueden aparecer en el medio marino y respetar las normas básicas de precaución, protección y seguridad.

c) Dominar el montaje y desmontaje de los materiales y del equipo.

d) Diferenciar las diferentes señales de manos en el buceo.

e) Experimentar habilidades específicas de iniciación del buceo.

f) Tomar conciencia del impacto que puede tener el buceo en el medio natural.

\section{Contenidos}

El bloque organizador de contenidos para esta UD es el de Actividades en el medio natural (Decreto 291/2007) aunque, el buceo también tiene relación con los otros bloques de contenidos (Juegos y deportes. Cualidades motrices personales; Condición física y salud). A continuación se presentan los contenidos específicos de la UD:

- Orígenes y evolución del buceo.

- Fundamentos físicos (principio de Arquímedes, presión) y fisiológicos (sistema respiratorio y cardiovascular y sus respuestas fisiológicas).

- Materiales (aletas, traje de buceo, botella, cinturón de lastre, tubo, máscara, escarpines, regulador, nanómetro) y medidas de seguridad necesarias para la práctica del buceo (antes, durante y después de la inmersión). Normativa vigente.

- Peligros que pueden aparecer en el medio marino (mareas, corrientes y fauna marina entre otros).

- Dominio del montaje (acoplamiento del chaleco a la botella, comprobación de la válvula, acoplamiento del regulador a la botella, entre otros) y desmontaje de los materiales y del equipo.

- Señales de manos en el buceo (señal para: problema, ascender, retornar, parar, preguntar cuánto aire, entre otras).

- Respeto de las normas básicas de precaución, protección y seguridad.

- Experimentación de habilidades específicas de iniciación del buceo (inmersión, actividad bajo el agua, procedimientos de salida, ascenso).

- Toma de conciencia del impacto que puede tener el buceo en el medio natural.

\section{Metodología}

Dentro de las técnicas de enseñanza propuestas por Delgado (1991), esta UD utiliza la instrucción directa y la indagación o búsqueda. Los estilos de enseñanza predominantes son los tradicionales (modificación del mando directo y asignación de tareas). También se trabajará con la estilos participativos, concretamente con la enseñanza reciproca. Se considera que ante los "peligros" del medio acuático este tipo de metodología es la más adecuada en esta UD de iniciación al buceo. Todas las intervenciones didácticas tendrán siempre presente, ante todo, la seguridad. El profesor en todo momento debe concienciar al alumnado del riesgo que supone el medio acuático. Por otro lado, 
se pretende implicar al estudiante lo máximo posible en la construcción de sus propios aprendizajes, persiguiendo que los discentes alcancen autonomía de forma progresiva.

\section{Recursos}

Los recursos materiales serán todo el material necesario para el buceo (botella, cinturón de lastre, tubo, máscara, regulador y nanómetro). Como instalaciones se utilizará la piscina municipal descubierta de Mazarrón y un aula para impartir los contenidos teóricos. Esta experiencia cuenta con la colaboración del Ayuntamiento de Mazarrón y la firma de un convenio con la escuela de Buceo. De este modo, la actividad resulta gratuita para el alumnado.

\section{Actividades de enseñanza-aprendizaje}

La presente UD consta de 3 sesiones, estructuradas de la siguiente manera:

\section{- Sesión 1. Introducción teórica}

En esta sesión se realizará una introducción teórica. También se hará una evaluación inicial mediante preguntas. Los contenidos que se tratarán serán los siguientes: orígenes y evolución del buceo; fundamentos físicos y fisiológicos del buceo; materiales y medidas de seguridad necesarias; peligros que pueden aparecer en el medio marino; toma de conciencia del impacto que puede tener el buceo en el medio natural. Por último, los alumnos visionarán un vídeo en el que muestran diferentes fondos marinos y las posibilidades que ofrece el municipio.

\section{- Sesión 2. El buceo}

Una vez que los alumnos tienen unas nociones básicas teóricas, practicarán el montaje y desmontaje de los materiales y del equipo. También conocerán las señales de manos en el buceo. Por último, realizarán unas actividades y juegos de iniciación al buceo en piscina.

\section{- Sesión 3. El buceo 2}

Se continuará con las actividades de iniciación al buceo y se realizará la evaluación final teórico-práctica.

\section{Evaluación}

A continuación se definen los siguientes indicadores de evaluación y criterios calificación (\%). Para ello, se han tenido en cuenta los objetivos didácticos y contenidos planteados:

Tabla 1. Indicadores de evaluación y criterios de calificación para la Unidad Didáctica

\begin{tabular}{|c|c|}
\hline Indicadores de evaluación y criterios calificación & $\%$ \\
\hline $\begin{array}{l}\text { - Conoce los orígenes y evolución del buceo, sus fundamentos físicos y fi- } \\
\text { siológicos. }\end{array}$ & 10 \\
\hline - $\quad$ Enumera los recursos materiales necesarios para la práctica del buceo. & 10 \\
\hline $\begin{array}{l}\text { - Conoce las medidas de seguridad necesarias para la práctica del buceo e } \\
\text { identifica los peligros que pueden aparecer en el medio marino. }\end{array}$ & 10 \\
\hline - $\quad$ Diferencia las diferentes señales de mano en el buceo. & 10 \\
\hline $\begin{array}{l}\text { - Realiza correctamente el montaje y desmontaje de los materiales y del } \\
\text { equipo. }\end{array}$ & 15 \\
\hline $\begin{array}{l}\text { - Participa activamente en las actividades y tareas propuestas respetando } \\
\text { las normas básicas de precaución, protección y seguridad. }\end{array}$ & 25 \\
\hline $\begin{array}{l}\text { - Valora y es consciente del impacto que puede causar el buceo en el me- } \\
\text { dio natural. }\end{array}$ & 20 \\
\hline
\end{tabular}

Como instrumentos de evaluación se utilizará una prueba escrita y varias escalas de clasificación para aquellos indicadores de evaluación más prácticos. 


\section{3.- CONCLUSIONES}

"Reconocer el medio natural como espacio idóneo para la actividad física, y discriminar aquellas prácticas que pueden causarle cualquier tipo de deterioro" (Decreto 291/2007) es uno de los objetivos que se pretenden conseguir al finalizar la etapa de ESO a través del área de Educación Física. Esta UD contribuye a la consecución de este objetivo proponiendo la práctica del buceo como una actividad física a realizar en el medio natural. En el contexto donde se ha llevado a cabo la UD, se considera que el buceo representa una actividad cercana al contexto del alumnado, atractiva y accesible. Todo ello sin olvidar el enfoque competencial perseguido por la legislación vigente en el que se pretende conseguir alumnos capaces de utilizar todos sus recursos personales para superar los desafíos que se encuentran en su vida diaria, en este caso practicar una AFMN como recurso para la ocupación constructiva de su tiempo libre y de ocio. Y es que con las AFMN el individuo pone en juego su desarrollo personal, debido al potencial cognoscitivo, afectivo y motriz de estas actividades (Arroyo, 2010).

\section{4.- REFERENCIAS}

Arroyo, M. D. (2010). Las Actividades físicas en el medio natural como recurso educativo. Revista Autodidacta de la Educación en Extremadura, 170-179.

Baena, A. y Granero, A. (2011). Contribución de las actividades físicas en el medio natural a la consecución de las competencias básicas. Trances, 3(5), 609-632.

Decreto 291/2007, de 14 de septiembre, por el que se establece el currículo de la Educación Secundaría Obligatoria en la Comunidad Autónoma Región de Murcia. BORM núm. 221. Lunes 24 de septiembre de 2007, 27179- 27303.

Delgado, M. A. (1991). Los estilos de enseñanza en Educación Física. Propuesta para una reforma de la enseñanza. Granada: Universidad de Granada.

Granero, A. y Baena, A. (2007). Importancia de los valores educativos de las actividades físicas en la naturaleza. Habilidad Motriz, 29, 5-14.

Granero, A., Baena, A., y Martínez, M. (2010). Contenidos desarrollados mediante las actividades en el medio natural de las clases de Educación Física en secundaria obligatoria. Revista Ágora para la Educación Física y el Deporte, 12(3), 273-288.

Guillén, R. Lapetra, S., y Casterad, J. (2000). Las actividades en el medio natural. Barcelona: Inde.

Funollet, F. (2004). La necesidad de las actividades deportivas en el medio natural. Tándem, 16,7-19.

Miguel, A. (2001). Actividades físicas en el medio natural en la educación física escolar. Palencia: PDM.

Real Decreto 1631/2006, de 29 de Diciembre, por el que se establecen las enseñanzas mínimas correspondientes a la ESO. BOE núm. 106. Viernes 5 de enero de 2007, 677-773.

Vaquero-Cristóbal, R., Martínez, M., Baena, A., Granero, A., y Sánchez, J. A. (2013). Progresión de los contenidos a enseñar en la Educación Secundaría Obligatoria dentro del bloque de actividades en el medio natural. Trances, 5(1), 39-50.

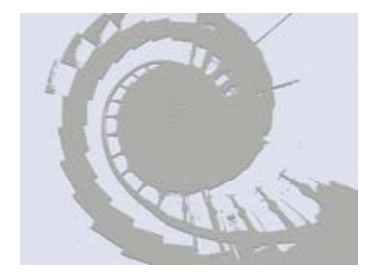

